\title{
Evidence for longer survival of patients with pleural mesothelioma without asbestos exposure
}

\author{
MR LAW, FG WARD, MARGARET E HODSON, BE HEARD
}

From the Cardiothoracic Institute and Brompton Hospital, London, and the Department of Health and Social Security

ABSTRACT In a group of 23 patients with histologically confirmed malignant mesothelioma of the pleura who could not recall exposure to asbestos dust, survival was significantly longer than in a group of 83 patients with known exposure. Asbestos bodies were found by a quantitative method significantly less frequently in the unexposed than in the exposed group. The longer survival of patients without known exposure could not be correlated with any significant difference in the histological cell types of the tumours from those of exposed patients. In the 83 patients with known exposure survival did not relate to duration of exposure. Consequently, although the tumours of patients unable to recall exposure may be caused by unrecognised environmental contamination with asbestos dust, the longer survival of these patients would suggest a different aetiology.

Malignant mesothelioma of the pleura is widely accepted as being frequently associated with a clinical history of exposure to asbestos dust, as reported in 1960 by Wagner et al. ${ }^{1}$ The proportion of men with pleural mesothelioma who have known asbestos exposure is generally $50-75 \%$ in European and North American series. ${ }^{23}$ In some cases of histologically confirmed mesothelioma, however, past occupational asbestos exposure can be eliminated, and there is no pathological evidence of exposure. ${ }^{3-6}$ We have compared the clinical and pathological features of patients with known asbestos dust exposure and of patients unable to recall exposure to determine whether the apparent difference in aetiology is reflected in any other differences.

\section{Patients and methods}

We sought clinical and pathological differences between cases of malignant mesothelioma of the pleura where a history of asbestos dust exposure had been confirmed and those where it had been denied. We had previously compiled a series of 115 cases of pleural mesothelioma after re-examination of sections of histological material (generally from thoracotomy or postmortem specimens), and

\footnotetext{
Address for reprint requests: Dr ME Hodson, Brompton Hospital, London SW3 6HP.
}

Accepted 1 July 1983 divided them into epithelial, sarcomatous, and mixed histological types. ${ }^{7}$ In 83 of these 115 cases a clear history of exposure to asbestos dust had been documented by the admitting doctor, and the duration and nature of exposure was recalled by most of the patients with little difficulty. Twenty three patients could not recall asbestos exposure despite close questioning and listing of all previous occupations. Exposure was inadequately documented in nine cases. From actuarial survival curves of the exposed and unexposed cases, comparison was made of standard errors of survival probabilities at six monthly intervals up to five years.

Postmortem specimens of lung tissue were available for $\mathbf{6 7}$ of the cases with known exposure and 11 of the cases without known exposure. Unstained $30 \mu$ sections of lung from three different sites in each case were prepared and examined as described by Doniach et al. ${ }^{8}$ They were classified as showing no asbestos bodies or occasional (1-5) or numerous bodies $(>5)$ per $1.5 \mathrm{~cm}$ square area of lung tissue.

\section{Results}

The survival period from first symptoms to death (fig and table 1) was significantly longer for the 23 patients who could not recall asbestos dust exposure than for the 83 patients with known exposure ( $p<0.01$ at 12 months and thereafter). There was also a significant difference in survival both from the time of hospital referral and from the time of dia- 


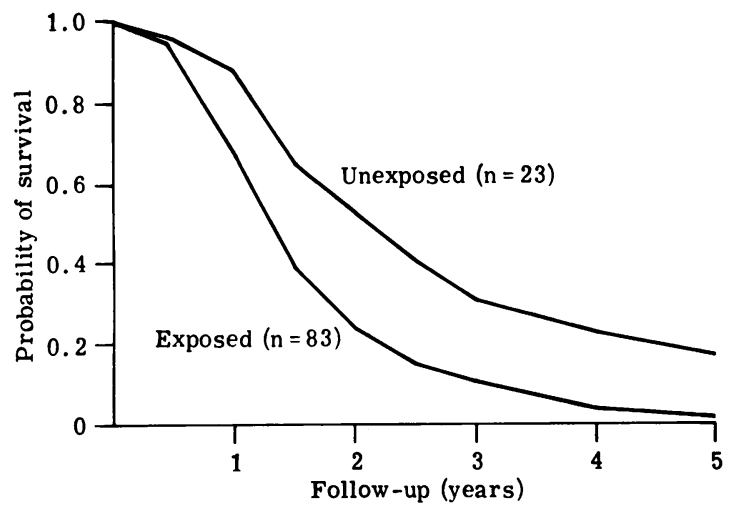

Actuarial survival curves comparing the duration of survival from first symptoms in cases of pleural mesothelioma with and without asbestos exposure.

Table 1 Clinical and histological features in patients with mesothelioma in relation to asbestos exposure

\begin{tabular}{lllc}
\hline & \multicolumn{3}{l}{ Asbestos exposure } \\
\cline { 2 - 4 } & Known & Not recalled & $\begin{array}{c}\text { Inadequately } \\
\text { documented }\end{array}$ \\
\hline $\begin{array}{l}\text { No of patients } \\
\text { Age (y): range } \\
\text { (mean) }\end{array}$ & 83 & 23 & 9 \\
$\begin{array}{l}\text { Sex: M/F } \\
\text { Histological type } \\
\text { (No (\%)) }\end{array}$ & $73 / 10$ & $13 / 10$ & $8 / 1$ \\
$\begin{array}{l}\text { Epithelial } \\
\text { Mixed }\end{array}$ & $42(51)$ & $12(52)$ & $6(67)$ \\
$\begin{array}{l}\text { Sarcomatous } \\
\text { Median survival } \\
\text { (months) }\end{array}$ & $20(24)$ & $7(30)$ & $2(22)$ \\
$\quad$ From first & & $4(17)$ & $1(11)$ \\
symptoms & 15 & & \\
From diagnosis & 10 & 25 & 16 \\
\hline
\end{tabular}

gnosis, although histological confirmation of the diagnosis was sometimes late in the course of the disease, and was deferred until necropsy in 10 cases. Subdivision of the exposed cases revealed no significant difference in survival from first symptoms between 14 patients with direct occupational exposure of a total duration of less than one year, one to five years, and more than five years, and 23 patients with indirect exposure, the last group including indirect occupational, paraoccupational, and neighbourhood exposure as defined in the Health and Safety Executive report. ${ }^{9}$

There was a significantly higher proportion of men among the 83 patients with known exposure than among the 23 unable to recall exposure (table 1) $\left(\mathrm{p}<0.01, \chi^{2}\right.$ test). There was no significant sex difference in survival, however, when groups with and without known exposure were examined separately, and the survival difference between patients with and without known exposure remained when men alone were examined. There were no significant differences in clinical features, age, or the distribution of histological types between patients with and without known exposure (table 1), and no histological differences between the two groups were detectable. The survival and sex ratio of the nine patients with inadequately documented exposure did not differ significantly from that of the exposed patients.

The numbers of asbestos bodies counted in unstained thick sections of lung tissue of patients subdivided according to duration of asbestos exposure is shown in table 2. Asbestos bodies were found significantly less frequently in lung tissue from patients who could not recall exposure than in lung from any of the four categories of exposed patients ( $p<0.05$, Fisher's exact test). The proportion of cases with numerous asbestos bodies in lung tissue showed a significantly increasing trend with increasing duration of asbestos exposure (demonstrated by a trend $\chi^{2}$ test). The proportion of cases with any asbestos bodies (that is, "occasional" and "numerous") showed a similar significantly increasing trend through the exposure groups.

\section{Discussion}

We first reported evidence of longer survival in patients who could not recall exposure to asbestos dust than in patients with known exposure in a smaller series of patients with mesothelioma in $1980 .{ }^{10}$ Hirsch et al have recently made the same observation in a series of 17 exposed and 10 unexposed

Table 2 Number of asbestos bodies in lung tissue and duration of exposure

\begin{tabular}{|c|c|c|c|c|c|}
\hline \multirow[t]{2}{*}{ Asbestos exposure (y) } & \multirow[t]{2}{*}{ No of cases } & \multicolumn{3}{|c|}{ Asbestos bodies per $1.5 \mathrm{~cm}$ square area of lung tissue } & \multirow{2}{*}{$\begin{array}{l}\text { Significance of difference from cases } \\
\text { with no exposure: } p \text { value* }\end{array}$} \\
\hline & & None & Occasional (1-5) & Numerous $(>5)$ & \\
\hline $\begin{array}{l}\text { None } \\
<1 \\
1-5 \\
>5 \\
\text { Indirect }\end{array}$ & $\begin{array}{l}11 \\
12 \\
12 \\
24 \\
19\end{array}$ & $\begin{array}{l}8 \\
2 \\
3 \\
4 \\
5\end{array}$ & $\begin{array}{r}3 \\
8 \\
6 \\
4 \\
12\end{array}$ & $\begin{array}{r}0 \\
2 \\
3 \\
16 \\
2\end{array}$ & $\begin{array}{l}p<0.05 \\
p<0.05 \\
p<0.001 \\
p<0.05\end{array}$ \\
\hline
\end{tabular}

${ }^{*}$ Fisher's exact test. 
patients. ${ }^{3}$ The validity of the negative exposure histories in the present study was supported by the demonstration of asbestos bodies in lung tissue significantly less frequently in the absence of known exposure. Previous studies have also shown that patients unable to recall asbestos exposure rarely have many asbestos bodies or a high asbestos fibre content in lung tissue. ${ }^{3-6}$ The difference in sex ratio, with significantly more men in the exposed group, was also observed by Hirsch $e t a l^{3}$ and can be related to more frequent occupational asbestos exposure in men than women. There was no evidence of shorter survival in men to explain the shorter survival of the exposed group. The unexposed patients reported by Hirsch et $\mathrm{al}^{3}$ were younger and had tumours of epithelial cell type more frequently than the exposed patients, although the differences were not significant. Our study provided no support for such an association and no evidence to support another reported association-namely, between asbestos exposure and tumours of mixed cell type. ${ }^{11}$

It is not certain whether in patients unable to recall past asbestos exposure mesothelioma is caused by the very small amounts of asbestos dust almost universally inhaled in the home or by other sources of environmental contamination. ${ }^{212}$ The longer survival of patients unable to recall exposure suggests a different aetiology, however, since survival showed no relationship to duration of exposure among patients with known asbestos exposure. Environmental contamination with asbestos was not associated with the development of mesothelioma in the study of Sheers and Coles, ${ }^{13}$ which established that the extensive use of asbestos in the naval dockyard in Plymouth produced no cases of mesothelioma among indoor workers in the dockyard, and no increased risk to the town population.

We wish to thank our clinical colleagues at the Brompton and London Chest Hospitals whose patients we studied, Mr T Buckley and staff of the histopathology departments, and Mrs N Murray and staff of the London Pneumoconiosis Medical Panel. Dr PR Greenfield, chief medical adviser, Social Security Medical Division, Department of Health and Social Security, and Dr RGB Williamson, principal medical officer, DHSS, kindly assisted and gave permission to publish material relating to asbestos body content in lung tissue. We also thank Dr AJ Newman Taylor for helpful comment, Miss $M$ Rehahn for performing the statistical analysis, and Miss S Hockley for typing the manuscript.

\section{References}

' Wagner JC, Sleggs CA, Marchand P. Diffuse pleural mesothelioma and asbestos exposure in the North Western Cape Province. Br J Ind Med 1960;17:26071.

${ }^{2}$ Health and Safety Executive. Asbestos: final report of the advisory committee. Vol 2. London: HMSO, 1979:31-3, 45-6.

${ }^{3}$ Hirsch A, Brochard P, De Cremoux $\mathrm{H}$, et al. Features of asbestos-exposed and unexposed mesothelioma. Am J Ind Med 1982;3:413-22.

${ }^{4}$ Whitwell F, Scott J, Grimshaw M. Relationship between occupations and asbestos fibre content of the lungs in patients with pleural mesothelioma, lung cancer and other studies. Thorax 1977;32:377-86.

${ }^{5}$ Hasan FM, Nash G, Kazemi $H$. The significance of asbestos exposure in the diagnosis of mesothelioma. Am Rev Respir Dis 1977;115:761-8.

${ }^{6}$ Milne JEH. Thirty two cases of mesothelioma in Victoria, Australia: a retrospective survey related to occupational asbestos exposure. $\mathrm{Br} \mathrm{J}$ Ind $\mathrm{Med}$ 1976;33:115-22.

${ }^{7}$ Law MR, Hodson ME, Heard BE. Malignant mesothelioma of the pleura: relationship between histological type and clinical behaviour. Thorax 1982;37:810-5

${ }^{8}$ Doniach I, Swettenham KV, Hathorn MKS. Prevalence of asbestos bodies in a necropsy series in East London: association with disease, occupation and domiciliary address. $\mathrm{Br} J$ Ind $\mathrm{Med}$ 1975;32:16-30.

${ }^{9}$ Health and Safety Executive. Asbestos: final report of the advisory committee. Vol 2. London: HMSO, 1979:11, 23-4, 66.

${ }^{10}$ Law MR, Heard BE, Hodson ME. Survival of patients with malignant mesothelioma. Thorax 1980;35:712.

"Magner D, McDonald AD. Malignant mesothelial tumors-histologic type and asbestos exposure. $N$ Engl J Med 1972;287:570-1.

12 Anonymous. Exposure to asbestos dust. $\mathrm{Br} \mathrm{Med} J$ 1976;i:1361-2.

${ }^{13}$ Sheers G, Coles RM. Mesothelioma risks in a naval dockyard. Arch Environ Health 1980;35:276-82. 